\title{
A Study on the Effect of Resizing Tick Size on Stock Prices Using the Event Study Method
}

\author{
Hiroyuki Maruyama *, Tomoaki Tabata ${ }^{\dagger}$, \\ Takaaki Hosoda *
}

\begin{abstract}
We analyzed the abnormal return (AR) and cumulative abnormal return (CAR) of tick resizing on the Tokyo Stock Exchange in 2014. Tick size is the unit by which price of a stock changes in the stock market. In our study, Phase 1 (P1) was marked for a price range higher than 3001 yen, and Phase 2 (P2) for a price range of 5000 yen or less. AR is the actual return minus the return when the tick size is not changed. CAR is the cumulative value of AR. As a result, in P1, CAR was positive and significant for many days, while in $\mathrm{P} 2$, it was negative and had many significant days. In addition, to analyze the difference between $\mathrm{P} 1$ and $\mathrm{P} 2$, the price range was divided, and the same analysis was repeated. CAR showed no significant negative or positive days in the common price range of 3001 to 5000 yen. However, CAR showed many positive days in the price range higher than 5001 yen in P1 and many negative days in the price range below 3000 yen in $\mathrm{P} 2$. These results suggest that the impact of tick resizing may vary significantly depending on the price range.
\end{abstract}

Keywords: tick size reduction, abnormal return, cumulative abnormal return, Tokyo Stock Exchange

\section{Introduction}

The Tokyo Stock Exchange (TSE) implemented tick resizing in 2014. Tick size refers to the amount by which price change occurs when an investor orders stock. The TSE reduced the tick size so that orders can be placed in finer increments. This was done only for some TOPIX 100 company stocks. The first reduction was applied if the price of the stock was more than 3,000 yen, and the second reduction was applied if the price of the stock was less than or equal to 5,000 yen. The first reduction in tick size was called Phase 1 (P1), and the second Phase 2 (P2), which was implemented on January 14, 2014 and July 22, 2014, respectively. There were two objectives to this. The first was to achieve price efficiency and the second was to improve liquidity. Price efficiency represents a state in which all the information available in the market is

\footnotetext{
* Waseda University, Tokyo, Japan

$\dagger$ Tokai University, Tokyo, Japan

* Advanced Institute of Industrial Technology, Tokyo, Japan
} 
reflected in the price. Liquidity implies that investors can buy and sell stocks in the market instantly at no additional cost. However, resizing the tick size also affects returns. There are several reasons for this. First, a smaller tick size means that the price unit for determining returns is also narrower. That is, when the subdivision width is discrete, the profit amount is determined by this unit. When tick size is reduced, the subdivision width also reduces, which in turn reduces returns. Likewise, improving liquidity lowers the transaction cost, which is the cost of buying and selling stocks, which again affects returns. Further, there is also the so-called illiquidity premium (also known as the liquidity premium), [3] wherein investors want higher returns on stocks that are difficult to buy or sell in the market (so-called illiquid stocks).

We conducted an event study analysis of the impacts of resizing tick size in the TSE. Event study analyzes how company-related events affect stock prices or corporate value. In practice, the impact is analyzed by calculating abnormal returns (AR) and cumulative abnormal returns (CAR). AR represent the degree of difference between the expected return and the actual return in the market. This shows how the event impacts the value of the company. CAR represents the cumulative value of AR. This study therefore proposes a method by which it is possible to analyze how resizing tick size impacts the value of stocks in the financial markets.

\section{Literature Review}

There are various studies on tick size reduction, most of which analyze liquidity. According to Ahn, Cai, Chan, and Hamao, there was no increase in trading volume on the TSE in 1998 [1]. Chakravarty, Wood, and Van Ness confirmed a reduction in spreads and depths [4]. Lau and McInish also confirmed a reduction in spread during the 1994 resizing of tick size at the Stock Exchange of Singapore [9]. Ronen and Weaver confirmed a decrease in volatility and spread at the American Stock Exchange in 1997, but could not confirm a decrease in depth [14]. Xiao and Yamamoto confirmed a decrease in depth on the TSE in 2014 [16].

In research on AR, Graham, Michaely, and Roberts confirmed an increase in AR at the 2014 NYSE [8]. Chou, Lee, and Chen confirmed a decrease in AR in the 1997 and 2001 New York Stock Exchange [5]. In Al-Yahyaee, AR decreased in the Muscat Securities Market [2]. Pachare and Rainer analyzed the impact of the Tick Size Pilot announcement rather than the actual resizing of tick size, but it was shown to have no impact [13]. We measured AR and CAR in actual tick resizing. Thus, there are two main contributions. One is that it targets the 2014 TSE (auction-type market adopted in many markets). Two, we obtained one factor that is different from results of previous studies.

Maruyama, Tabata, and Hosoda also conducted a similar research [11]. However, although they are analyzing how tick resizing affected AR, they have not been able to analyze the factors underlying the difference in $\mathrm{P} 1$ and $\mathrm{P} 2$ results. However, we made some speculations about the cause by splitting the stocks by price range.

\section{$3 \quad \mathrm{AR}$ and $\mathrm{CAR}$}

Suppose an event occurs in the securities market, and as a result, it affects the value and stock price of the company. In such a case, in addition to the originally obtained return, an additional return from the event is obtained. AR represents this added return and is estimated by the formula below.

$A R_{n t}=r_{n t}-\widehat{r_{n t}},(1)$ 
where, $A R_{n t}$ represents the $\mathrm{AR}$ of stock $\mathrm{n}$ on day $\mathrm{t}, r_{n t}$ represents the actual logarithmic return of stock $\mathrm{n}$ on day $\mathrm{t}$, and $\widehat{r_{n t}}$ represents the predicted value of return of stock $n$ on day $t$.

In addition, CAR represents the total AR from day $t_{1}$ to day $t$. It is estimated by the following formula.

$C A R_{n t}=\sum_{\tau=t_{1}}^{t} A R_{n \tau},(2)$

Here, $C A R_{n t}$ represents the CAR of stock $\mathrm{n}$ on day $\mathrm{t}$, and $A R_{n t}$ represents the $\mathrm{AR}$ of stock $\mathrm{n}$ on day $\mathrm{t}$.

\section{Data and Method}

\subsection{Data}

As sample stocks, only stocks that meet some conditions were selected. We included 100 TOPIX stocks in the target price range for tick size resizing. This is because tick resizing can happen only for some stocks. Another condition is that there must be at least one transaction. If the price is less than 100 yen or more than 30,000 yen, it is excluded. These conditions are established to exclude stocks of different natures when analyzed. The conditions are in accordance with Ahn, Cai, Chan, and Hamao [1]. The number of stocks was 38 in P1 and 83 in P2. We set 2 months as the window for parameter estimation (44 business days from October 11, 2013, to December 13, 2013 in P1, and 43 business days from April 21, 2014, to June 23, 2014, in P2). We also set 2 months as the event window for calculating AR (35 business days from December 16, 2013, to February 10, 2014, in P1 and 40 business days from June 24, 2014, to August 19, 2014, in P2). This follows Maruyama, Tabata, and Hosoda [11]. The data were obtained from Datastream.

\subsection{Method}

First, we calculate the AR. Although there are various calculation methods such as CAPM [10] [12] [15] and 3 Factor model [7], we follow Dyckman, Philbrick, and Stephan, and use the Market Model [6]. We use the estimation period data for estimation. The Market Model is denoted by the following equation.

$\widehat{r_{n t}}=\widehat{\beta_{0}}+\widehat{\beta_{1}} r_{m t}$

where $r_{m t}$ is the market return (we use TOPIX and Nikkei 225) and $\widehat{\beta_{0}}$ and $\widehat{\beta_{1}}$ are the coefficients.

Next, we calculate the CAR based on the obtained AR. We use the first day of the event window as $t_{1}$. Then, on each day, we perform a t-test to see if the mean is equal to 0 .

We perform the same analysis as above for each price range. $\mathrm{P} 1$ refers to stocks in the price range of 3001 yen to 5000 yen and stocks in the price range of 5001 yen or more; P2 refers to stocks in the price range of 3,000 yen or less, and stocks in the price range of 3001 to 5000 yen. At this 
Table 1: Result of AR and CAR in P1 (all stocks) [11].

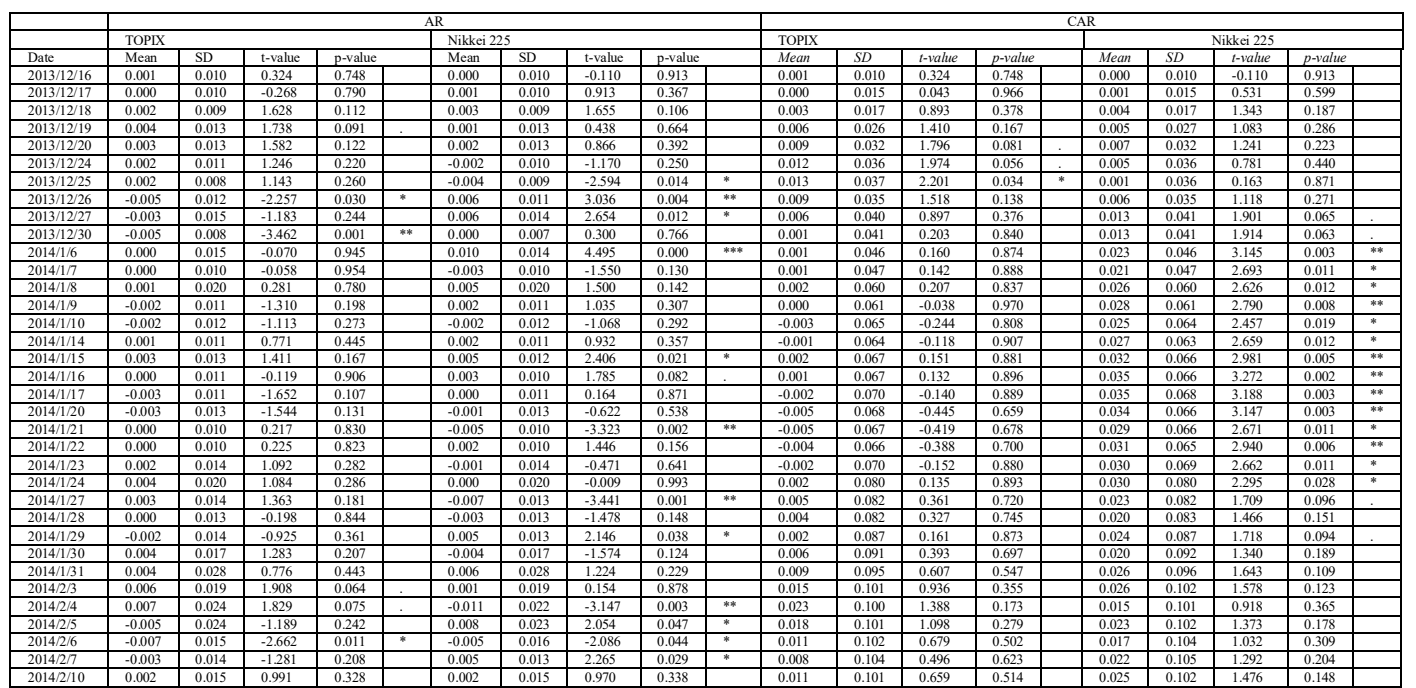

Note: SD is an abbreviation for standard deviation. $* * *$ is significant at the 0.001 level, $* *$ is significant at the 0.01 level, * is significant at the 0.05 level, and . is significant at the 0.1 level.

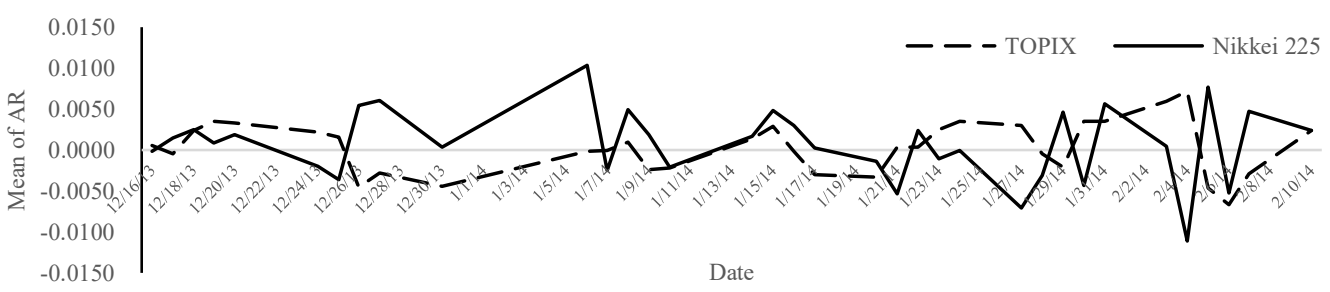

Figure 1: Movement of AR in P1 (all stocks) [11].

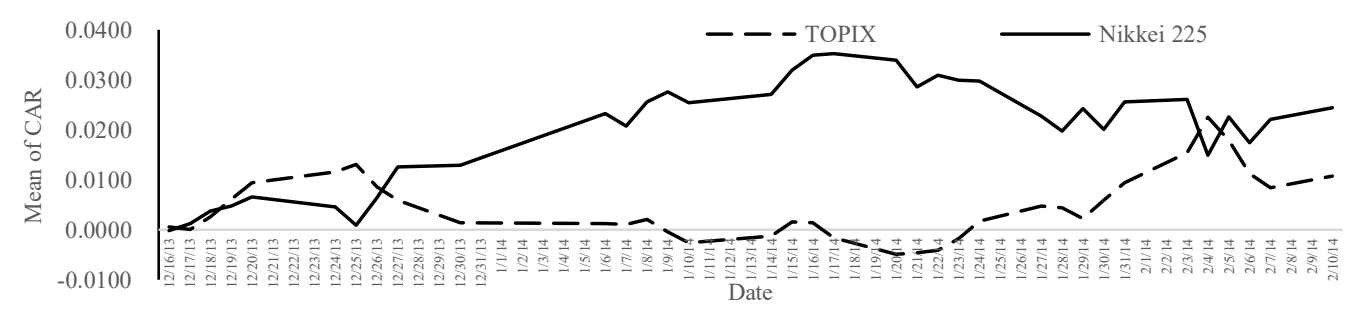

Figure 2: Movement of CAR in P1 (all stocks) [11].

time, we target only those stocks whose prices are all included in the price range during the target period. This makes it possible to analyze the difference in the impact of $\mathrm{P} 1$ and $\mathrm{P} 2$ price ranges separately.

\section{Results}

In P1, the results are as shown in Table 1, and the fluctuations over time are as shown in Figures 1 and 2. When we use TOPIX, the number of days when AR took a positive and significant value was 3 days and a negative and significant value was 3 days. CAR took a positive and significant value for 3 days, and a negative and significant value for 0 days. In addition, when we use Nikkei 
Table 2: Result of AR and CAR in P2 (all stocks) [11].

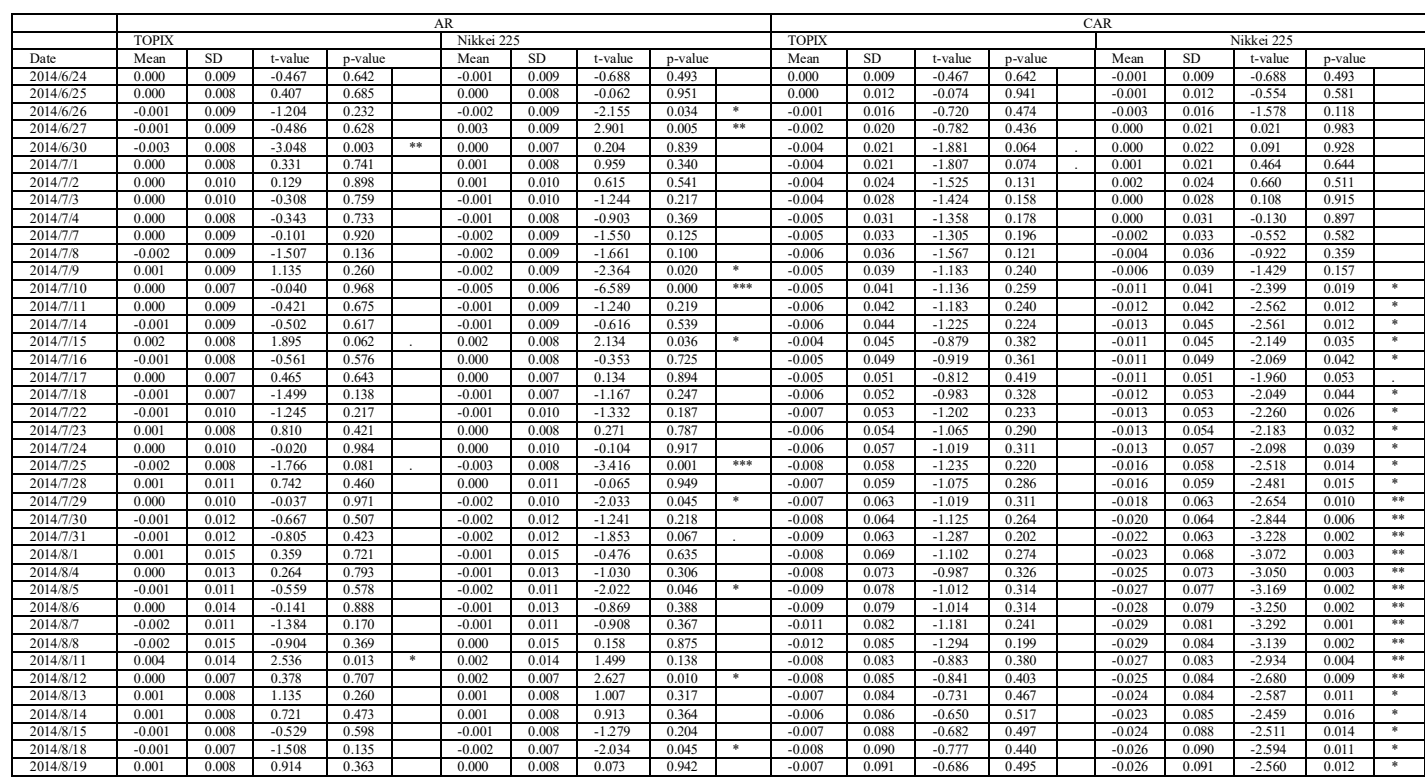

Note: *** is significant at the 0.001 level, $* *$ is significant at the 0.01 level, $*$ is significant at the 0.05 level, and . is significant at the 0.1 level.

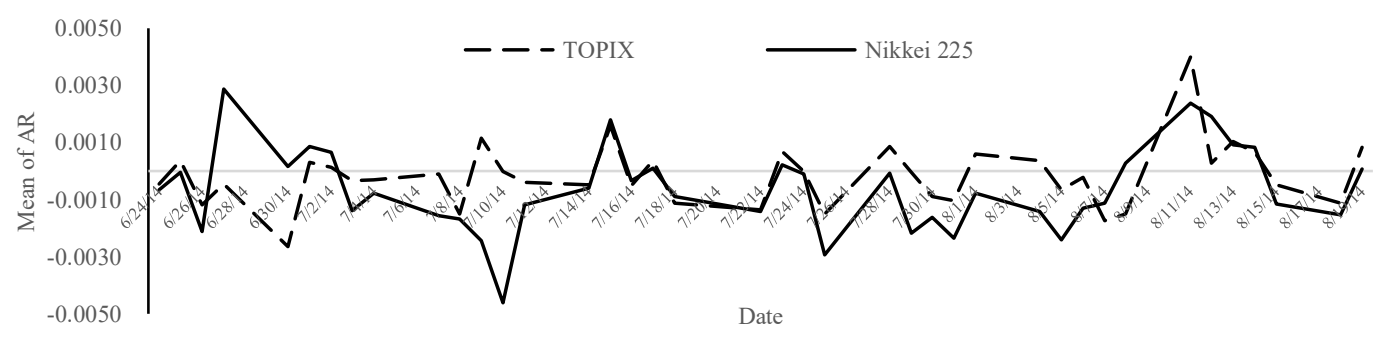

Figure 3: Movement of AR in P2 (all stocks) [11].

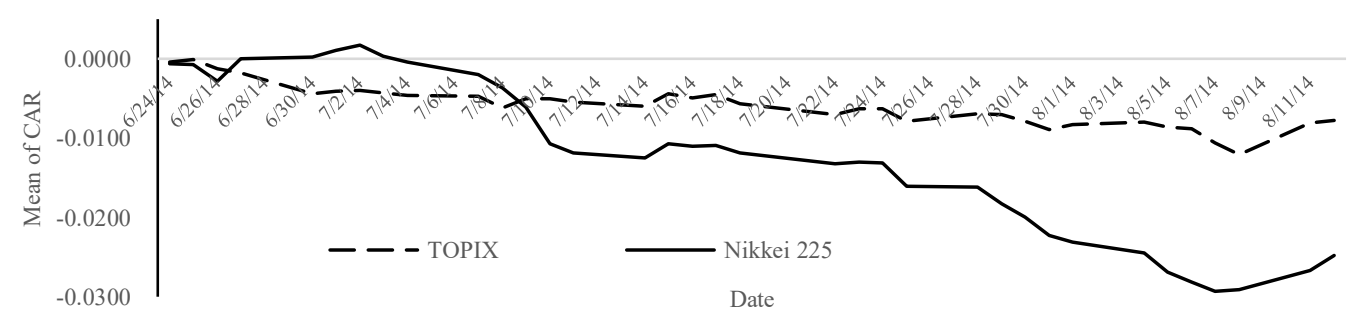

Figure 4: Movement of CAR in P2 (all stocks) [11].

225, AR took a positive and significant value for 8 days and a negative and significant value for 5 days. CAR took a positive and significant value for 18 days and a negative and significant value for 0 days. In P2, the results are as shown in Table 2, and the fluctuations are as shown in Figures 3 and 4 . When we use TOPIX, AR took a positive and significant value for 2 days and a negative and significant value for 2 days. CAR took a positive and significant value for 0 days and a negative and significant value for 2 days. Further, when we use Nikkei 225, AR took a positive and significant value for 3 days and a negative and significant value for 9 days. CAR took a positive and significant value for 0 days and a negative and significant value for 28 days. 
Table 3: Result of AR in P1 (from 3001 yen to 5000 yen and higher than 5001 yen)

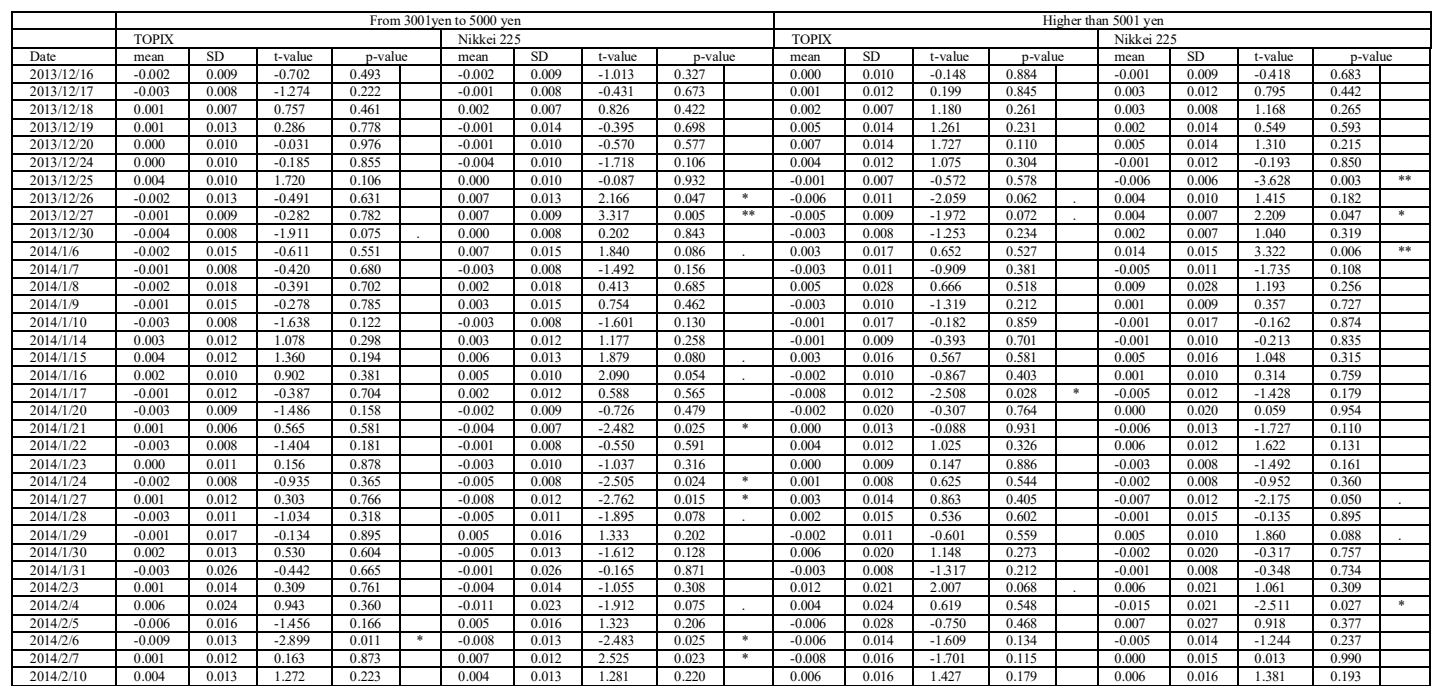

Note: $* *$ is significant at the 0.01 level, $*$ is significant at the 0.05 level, and . is significant at the 0.1 level.

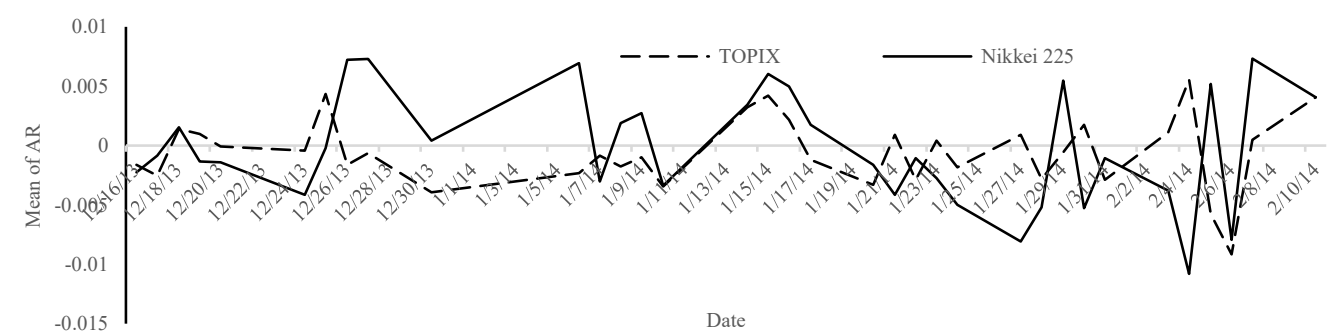

Figure 5: Movement of AR in P1 (from 3001 yen to 5000 yen)

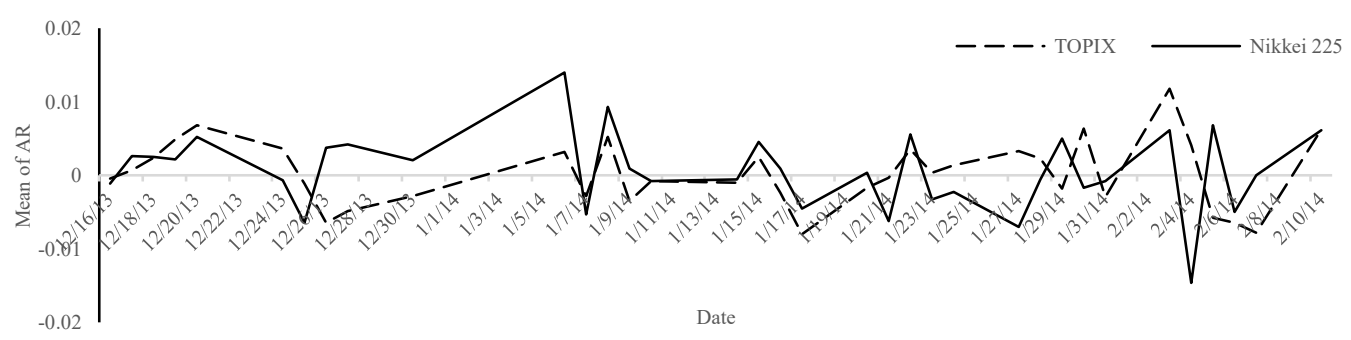

Figure 6: Movement of AR in P1 (than 5001 yen)

Next, the price range was divided. In P1, the results are as shown in Tables 3 and 4, and the time fluctuations are as shown in Figures 5, 6, 7, and 8. The number of stocks were 16 from 3001 to 5000 yen, and 13 higher than 5001 yen. When we use TOPIX for the price range of 3001 to 5000 yen, AR took a positive and significant value for 0 days and a negative and significant value for 2 days. CAR took a positive and significant value for 0 days and a negative and significant value for 0 day. When we use Nikkei 225, AR took a positive and significant value for 6 days and a negative and significant value for 6 days. CAR took a positive and significant value for 0 days and a negative and significant value for 0 days as well. When we use TOPIX for the price range higher than 5001 yen, AR took a positive and significant value for 1 day and a 
negative and significant value for 3 days. CAR took a positive and significant value for 0 days and a negative and significant value for 0 days. When we use Nikkei 225, AR took a positive and

Table 4: Result of CAR in P1 (from 3001 yen to 5000 yen and higher than 5001 yen)

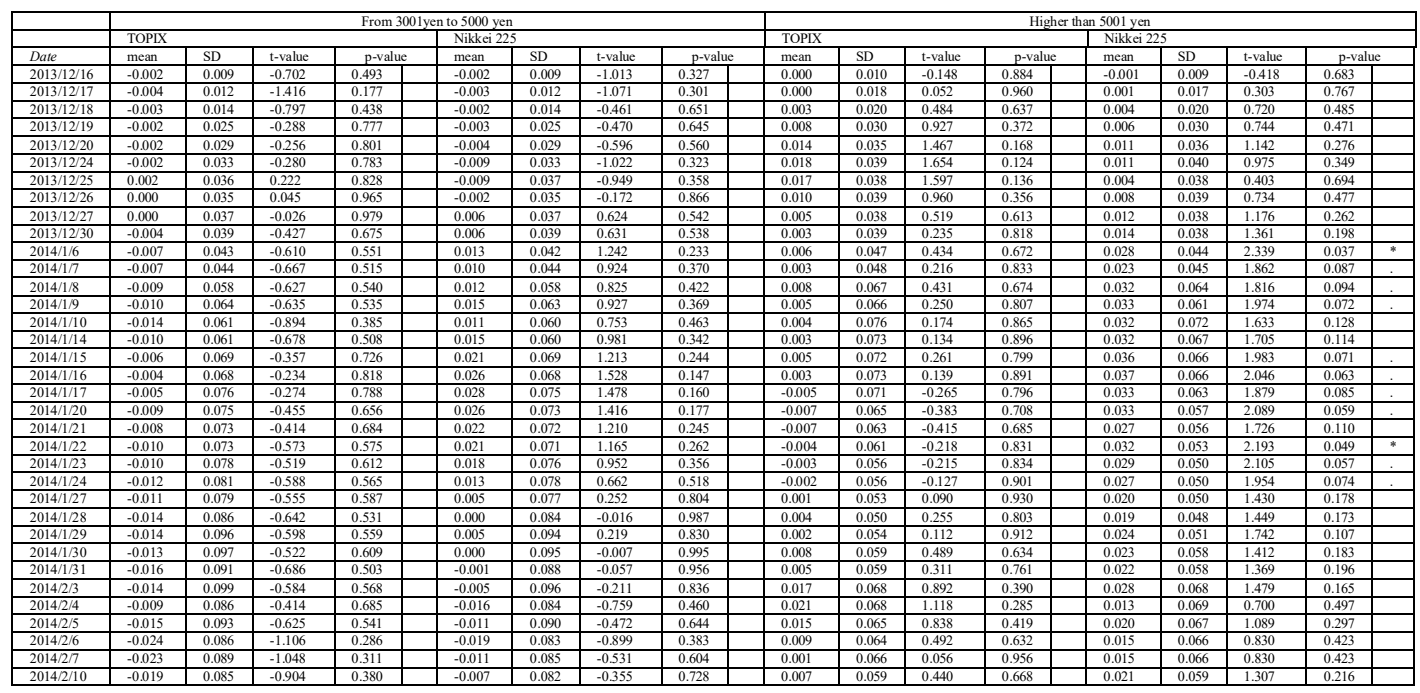

Note: * is significant at the 0.05 level, and . is significant at the 0.1 level.

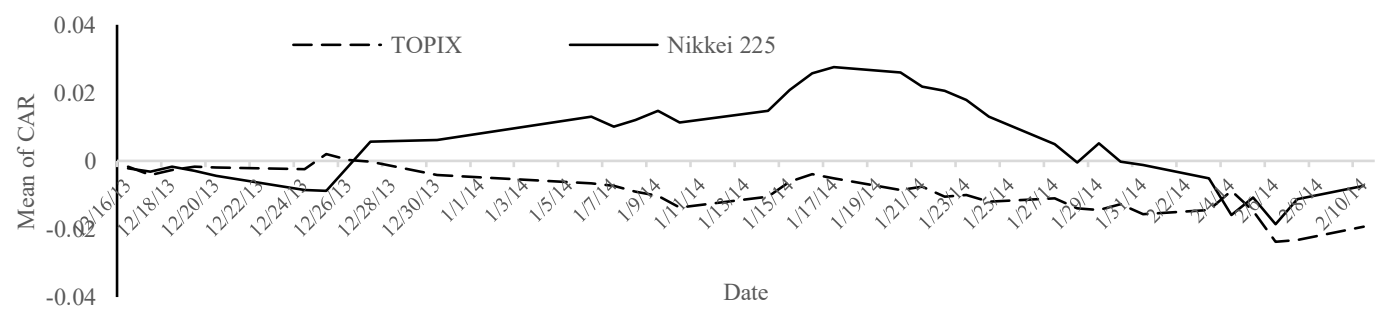

Figure 7: Movement of CAR in P1 (from 3001 yen to 5000 yen)

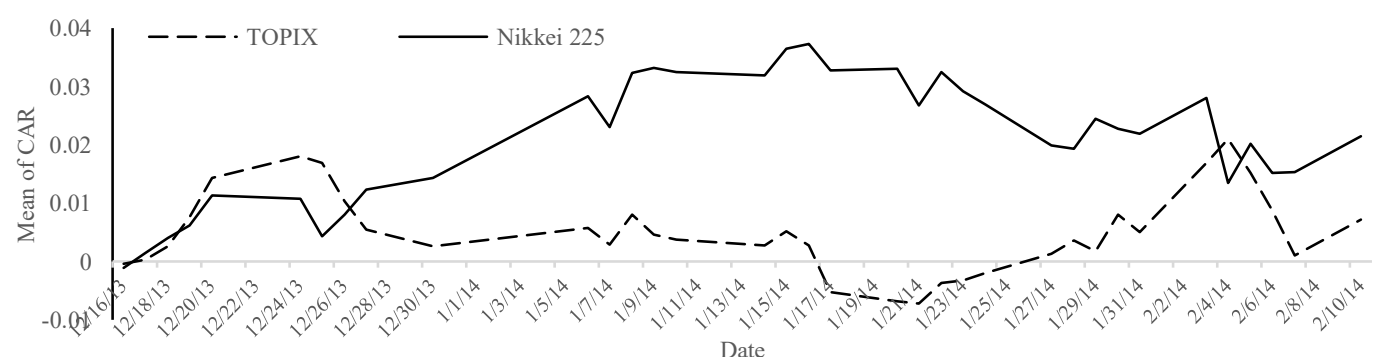

Figure 8: Movement of CAR in P1 (than 5001 yen)

significant value for 3 days and a negative and significant value for 3 days. CAR took a positive and significant value for 11 days and a negative and significant value for 0 days.

Similarly, in P2, the results are as shown in Tables 5 and 6, and the time fluctuations are as shown in Figures 9, 10, 11, and 12. The number of stocks was 53 stocks for 3000 yen or less and 18 stocks for 3001 to 5000 yen. When we use TOPIX for the price range of 3000 yen or less, the AR took a positive and significant value for 1 day and a negative and significant value for 3 days. CAR took a positive and significant value for 0 days and a negative and significant value for 23 
days. When we use Nikkei 225, AR took a positive and significant value for 2 days and a negative and significant value for 10 days. CAR took a positive and significant value for 0 days and a negative and significant value for 32 days. When TOPIX was used for the price range of

Table 5: Result of AR in P2 (lower than 3000 yen and from 3001 yen to 5000 yen)

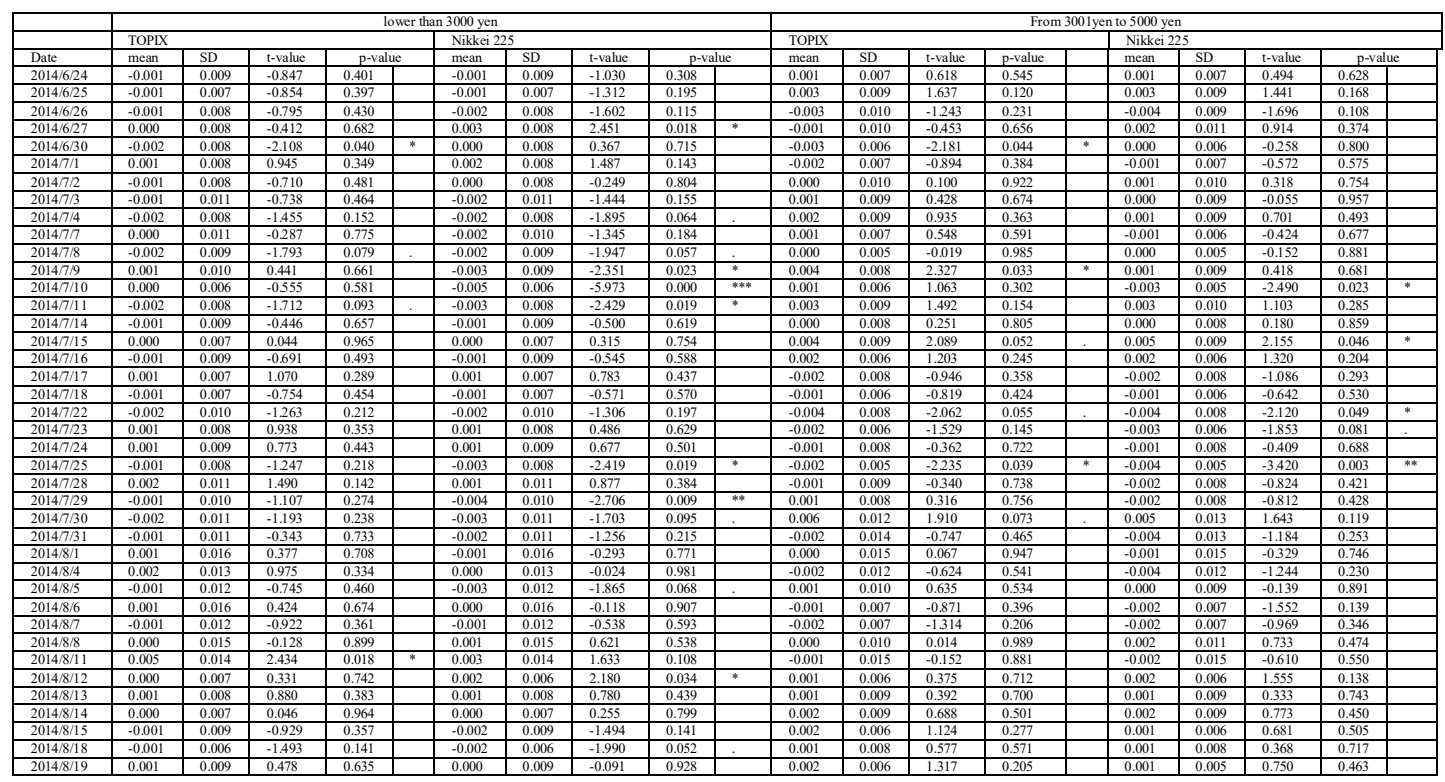

Note: $* * *$ is significant at the 0.001 level, $* *$ is significant at the 0.01 level, $*$ is significant at the 0.05 level, and . is significant at the 0.1 level.

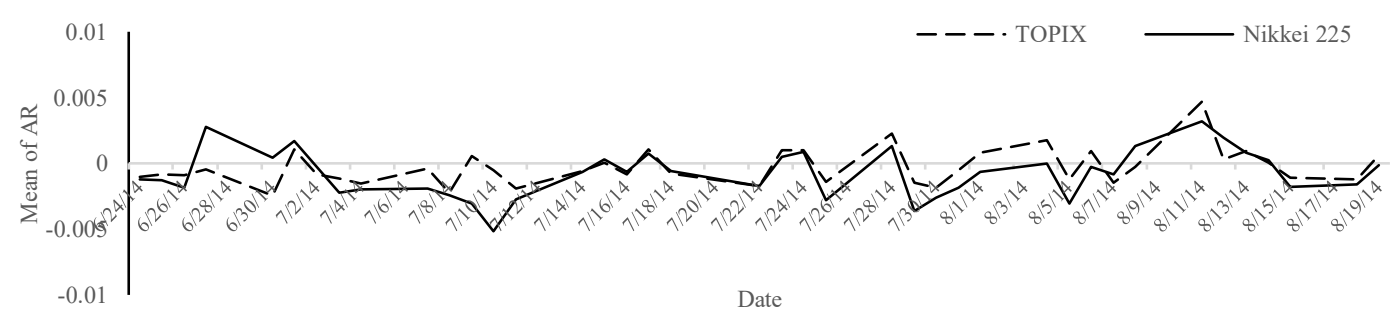

Figure 9: Movement of AR in P2 (less 3000 yen)

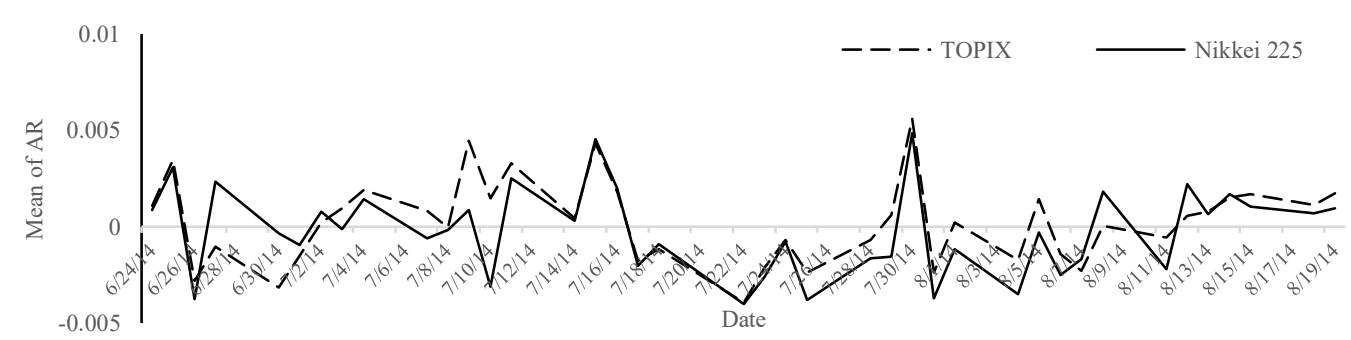

Figure 10: Movement of AR in P2 (from 3001 yen to 5000 yen)

3001 to 5000 yen, AR took a positive and significant value for 3 days and a negative and significant value for 3 days as well. CAR took a positive and significant value for 0 days and a negative and significant value for 0 days. When we use Nikkei 225, AR took a positive and 
significant value for 1 day and a negative and significant value for 4 days. CAR took a positive and significant value for 0 days and a negative and significant value for 0 days.

\section{Discussions}

Table 6: Result of CAR in P2 (lower than 3000 yen and from 3001 yen to 5000 yen)

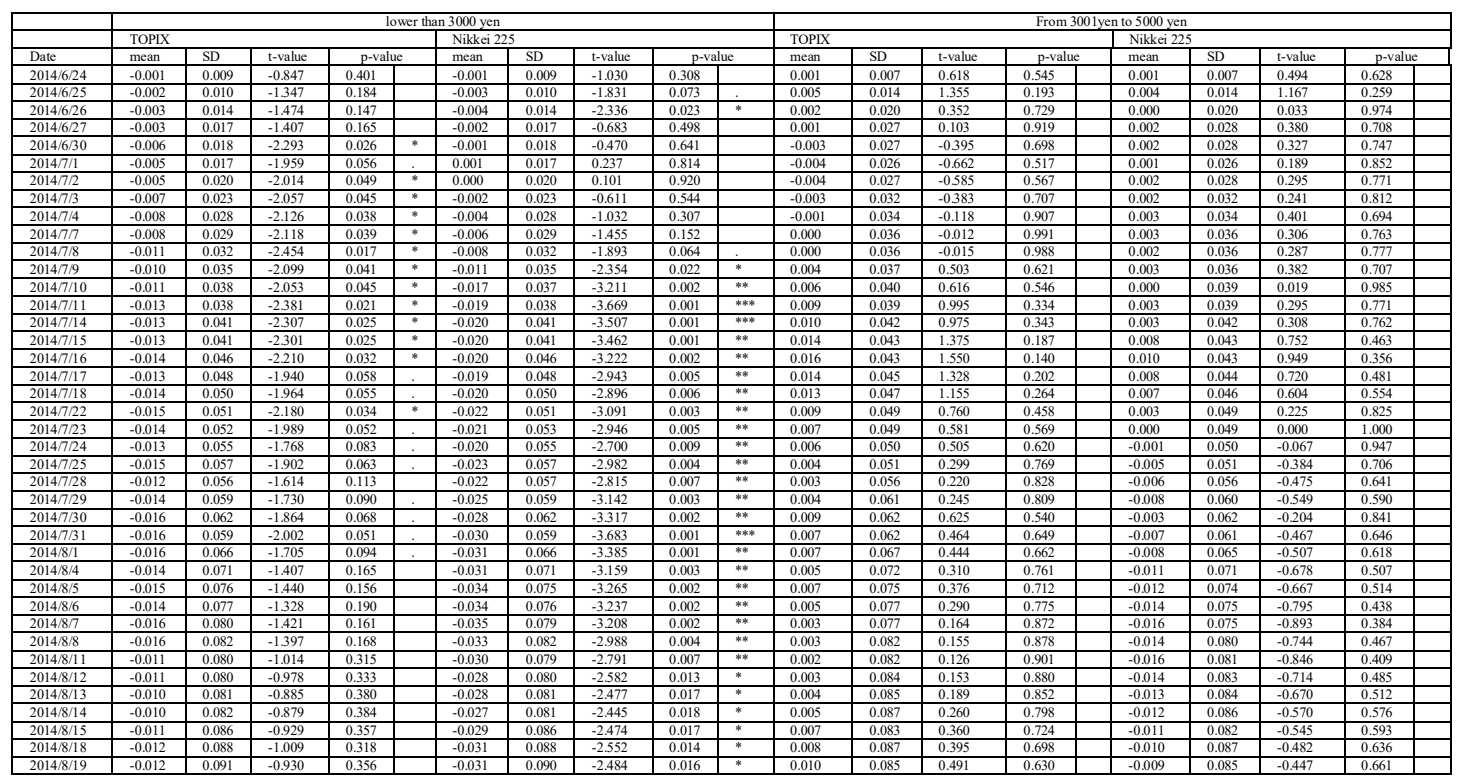

Note: *** is significant at the 0.001 level, ** is significant at the 0.01 level, * is significant at the 0.05 level, and . is significant at the 0.1 level.

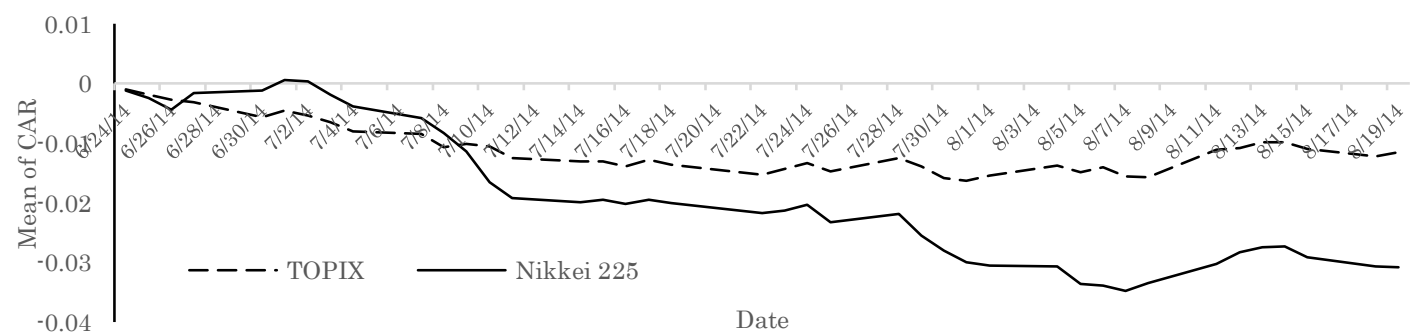

Figure 11: Movement of CAR in P2 (less than 3000 yen)

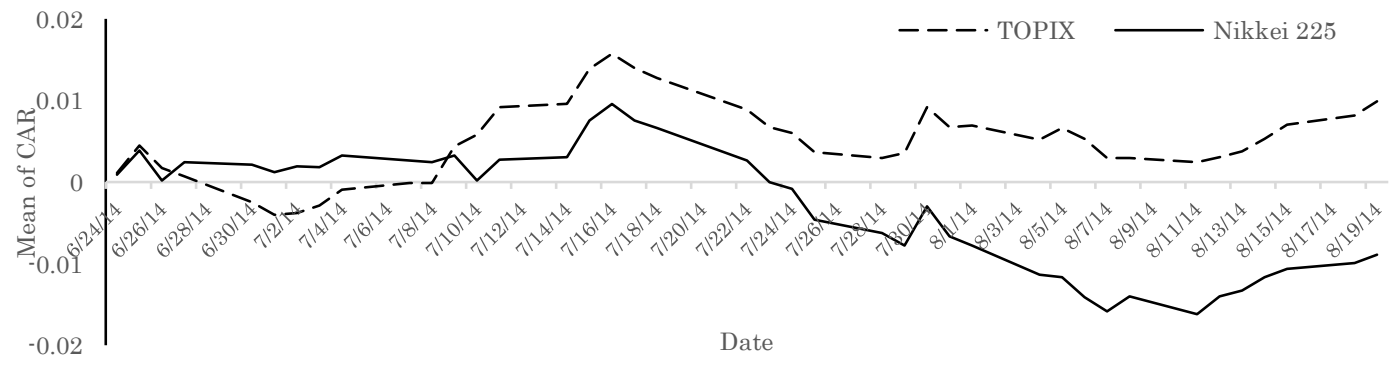

Figure 12: Movement of CAR in P2 (from 3001 yen to 5000 yen) 
We analyzed AR and CAR for all stocks when the price range was divided. At that time, we analyzed the case using TOPIX and Nikkei 225 as market returns. Table 7 summarizes the results. In P1, for all stocks, in the case of TOPIX, the number of days when AR was positive and significant was found to be equal to the number of days when AR was negative and significant; in the case of Nikkei 225, the number of positive days was higher. CAR showed more positive days in both TOPIX and Nikkei 225. In P2, in the case of TOPIX, the number of days when AR

Table 7: Summary of Results.

\begin{tabular}{|c|c|c|c|c|c|c|c|c|c|c|}
\hline & \multirow{2}{*}{\multicolumn{2}{|c|}{ price range (yen) }} & \multicolumn{4}{|c|}{$\mathrm{P} 1$} & \multicolumn{4}{|c|}{$\mathrm{P} 2$} \\
\hline & & & \multicolumn{2}{|c|}{ TOPIX } & \multicolumn{2}{|c|}{ Nikkei 225} & \multicolumn{2}{|c|}{ TOPIX } & \multicolumn{2}{|c|}{ Nikkei 225} \\
\hline & above & up to & + & - & + & - & + & - & + & - \\
\hline \multirow[t]{4}{*}{$\mathrm{AR}$} & \multicolumn{2}{|c|}{ all stocks } & 3 & 3 & 8 & 5 & 2 & 2 & 3 & 9 \\
\hline & 0 & 3000 & & & & & 1 & 3 & 2 & 10 \\
\hline & 3001 & 5000 & 0 & 2 & 6 & 6 & 3 & 3 & 1 & 4 \\
\hline & 5001 & - & 1 & 3 & 3 & 3 & & & & \\
\hline \multirow[t]{4}{*}{ CAR } & \multicolumn{2}{|c|}{ all stocks } & 3 & 0 & 18 & 0 & 0 & 2 & 0 & 28 \\
\hline & 0 & 3000 & & & & & 0 & 23 & 0 & 32 \\
\hline & 3001 & 5000 & 0 & 0 & 0 & 0 & 0 & 0 & 0 & 0 \\
\hline & 5001 & - & 0 & 0 & 11 & 0 & & & & \\
\hline
\end{tabular}

Note: The numbers in the table represent the number of days the mean was significant. In addition, + indicates that the average value is significant when the value is positive, and indicates that the average value is significant when the value is negative.

was positive and significant was equal to the number of days when AR was negative and significant; in Nikkei 225, there were more negative days. CAR showed more negative days for both. From these results, it may be inferred that resizing tick size had different impacts on P1 and $\mathrm{P} 2$. That is, there was a positive impact on P1 and a negative impact on P2. One reason for this could be that the target price ranges are different in $\mathrm{P} 1$ and $\mathrm{P} 2$.

Next, the price range was divided. P1 and P2 have the same price of 3001 to 5000 yen, and if in P1 the price is higher than 5001 yen and in P2 the price is lower than 3000 yen, the same results hold good.

Regarding the price range of 3001 to 5000 yen, in P1, in the case of TOPIX, there were more days with negative AR, and in Nikkei 225, the number of positive and significant days was equal to the number of negative and significant days. For CAR, it was 0 days for both TOPIX and Nikkei 225. In P2, in the case of TOPIX, the number of positive and significant days was equal to the number of negative and significant days, and in Nikkei 225, the number of days with negative AR was higher. For CAR, it was 0 days for both TOPIX and Nikkei 225. From these results, the difference between the number of days that were significant between plus and minus was 3 days at the most, and in many cases, there was almost no difference. These results suggest that there is no difference in the impact of resizing the tick size between P1 and P2, and that the difference between the positive and negative impacts and the degree of the difference are not large. In particular, for CAR, both minus and plus were 0 days. This suggests that there would be no impact in the long term.

When in P1 the price range was higher than 5001 yen, in the case of TOPIX, the number of days with negative AR was higher, and in the case of Nikkei 225, the number of positive and significant days was equal to the number of negative and significant days. Regarding CAR, in 
the case of TOPIX, the number of positive and negative significant days was 0 , and in the case of Nikkei 225, the number of positive and significant days was much higher. These results show that, when one day is used as a unit, the number of days in which a value that fluctuates significantly in a specific direction of plus or minus appears is small, it has a positive impact on corporate value in the long run. This suggests that tick resizing is effective in the high price range.

In the case of P2 of 3000 yen or less, AR was more negative in both TOPIX and Nikkei 225, especially in Nikkei 225. For CAR, both TOPIX and Nikkei 225 had much more negative and significant days. These results show that when one day is used as a unit, price fluctuates significantly in a specific negative direction, which has a negative impact on corporate value even in the long run. This suggests that tick resizing does not produce the desired results at low prices.

\section{Conclusion}

We conducted an AR and CAR analysis of tick resizing that was implemented in the TSE in 2014. In addition, when we conducted the analysis, we divided the price range and performed the same verification. This is because the target price range is different between P1 and P2. As a result, different results were obtained for P1 and P2. In P1, CAR was positive, while in P2 it was negative.

Further, in terms of the divided price range, in the price range of 3001 to 5000 yen, which is the common part, there was not much difference in the results between P1 and P2, and the number of significant CAR days was 0 in both. In P1, when price range was higher than 5001 yen, CAR had many positive days and a desirable impact in the long run. However, in the case of P2 of 3000 yen or less, CAR was negative for many days, which was an undesired result.

These results indicate that tick size should not be small for any stock, but that it is necessary to select the target stock. In such a case, the price range can be one condition. For future research, we would like to create a theoretical model of tick size and verify whether there are any other factors that affect it.

\section{References}

[1] H. J. Ahn, J. Cai, and K. Chan, and Y. Hamao, "Tick Size Change and Liquidity Provision on the Tokyo Stock Exchange," Journal of the Japanese and International Economies, vol. 21, no. 2, 2007 pp. 173-194.

[2] K. H. Al-Yahyaee, "The Effect of a Reduction in Price Discreteness on Ex-Day Stock Returns in a Unique Environment," Journal of International Financial Markets, Institutions and Money, vol. 23, 2013, pp. 283-294.

[3] Y. Amihud, "Illiquidity and Stock Returns: Cross-Section and Time-Series Effects," Journal of Financial Markets, vol. 5, no. 1, 2002, pp. 31-56.

[4] S. Chakravarty, R. A. Wood, and R. A. Van Ness, "Decimals and Liquidity: A Study of the NYSE," The Journal of Financial Research, vol. 27, no. 1, 2004, pp. 75-94. 
[5] R. K. Chou, W. C. Lee, and S. S. Chen, "The Market Reaction around Ex-Dates of Stock Splits Before and After Decimalization," Review of Pacific Basin Financial Markets and Policies, vol. 08, no. 2, 2015, pp. 201-216.

[6] T. Dyckman, D. Philbrick, and J. Stephan, "A Comparison of Event Study Methodologies Using Daily Stock Returns: A Simulation Approach,” Journal of Accounting Research, vol. 22, 1984, pp. 1-30.

[7] E. F. Fama, and K. R. French, "Common Risk Factors in the Returns on Stocks and Bonds," Journal of Financial Economics, vol. 33, no. 1, pp. 3-56, 1993

[8] J. R. Graham, R. Michaely, and M. R. Roberts, "Do Price Discreteness and Transactions Costs Affect Stock Returns? Comparing Ex-Dividend Pricing before and after Decimalization," The Journal of Finance, vol. 58, no. 6, 2003, pp. 2611-2636

[9] S. T. Lau and T. H. McInish, "Reducing tick size on the Stock Exchange of Singapore," Pacific-Basin Finance Journal, vol. 3, no. 4, 1995, pp. 485-496.

[10] J. Lintner, "The Valuation of Risk Assets and the Selection of Risky Investments in Stock Portfolios and Capital Budgets," The Review of Economics and Statistics, vol. 47, no. 1, 1965, pp. 13-37.

[11] H. Maruyama, T. Tabata, and T. Hosoda, "Abnormal Return and Tick Size Reduction in Tokyo Stock Exchange," 9th International Congress on Advanced Applied Informatics (IIAI-AAI), 2020, pp. 745-751.

[12] J. Mossin, "Equilibrium in a Capital Asset Market," Econometrica, vol. 34, no. 4, 1966, pp. 768-783.

[13] S. Pachare and I. Rainer, "Does the Tick Size Affect Stock Prices? Evidence from the Tick Size Pilot Announcement of the Test Groups and the Control Group," Working Paper, 2018.

[14] T. Ronen and D. G. Weaver, “Teenies' anyone?” Journal of Financial Markets, vol. 4, no. 3, 2001, pp. 231-260.

[15] W. F. Sharpe, "Capital Asset Prices: A Theory of Market Equilibrium under Conditions of Risk," The Journal of Finance, vol. 19, no. 3, 1964, pp. 425-442.

[16] X. Xijuan and R. Yamamoto, "Price Discovery, Order Submission, and Tick Size during Preopen Period," Pacific-Basin Finance Journal, vol. 63, 2020 (Forthcoming) 